\title{
Prospects of Investment Activity of Industrial Corporations in the Conditions of the Transformational Stage of Economic Development and Cooperation
}

\author{
Petr A. Levchaev \\ Department of Finance and credit \\ Mordovian State University named after Ogaryov \\ Saransk, Russia \\ levchaevpa@yandex.ru
}

\author{
Khezazna Badar \\ Department of Finance and credit \\ Mordovian State University named after Ogaryov \\ Saransk, Russia \\ khezazna.badar@gmail.com
}

\author{
Al-Shaeli Mohammed H.K. \\ Department of Finance and credit \\ Mordovian State University named after Ogaryov \\ Saransk, Russia \\ mohamadwasity@yahoo.com
}

\begin{abstract}
The study of the problems of investment activity of corporations in the conditions of the transformational stage of economic development and cooperation is currently quite relevant. This is due to the ongoing processes of globalization and the formation of the digital economic system in developed countries. In a market economy, there are various ways to attract resources for investment purposes. However, given the limited financial resources available, any economic structure always tries to find the best option. In this regard, investments are the most important economic resource that determines the efficiency and competitiveness of economic entities at different levels in the conditions of modern business cooperation and constant changes. Investment activity contributes to the formation of new jobs; increase the level of income and quality of life of the population.

The research methods are abstract analysis and synthesis, comparison and comparison. The theoretical and methodological basis of the research is the works of economists on the problems of Finance and financial resources, financial management and corporate planning.

As a result of research it is established that the formalized part of process of management of investment resources represents sequence of procedures of regulation, planning, the account, the analysis, regulation. Their closed, repetitive nature is considered as a phase of the management cycle. The interrelation of the system components (components of different levels and specifics) is a financial mechanism of an economic entity that ensures its optimal functioning. Project financing is considered as a system of many elements (participants, financing facilities, contracts, risk management, infrastructure), ensuring the efficiency of financial flows. It is necessary to focus project
\end{abstract}

financing on sustainable economic growth and innovative development. The implementation of investment financing projects with the participation of the state and private investors is a promising mechanism for infrastructure development in conditions of limited budget sources. Effective mechanisms for financing investment projects with the participation of the state are: the mechanism of deferred tax payments; the life cycle contract; the mechanism of infrastructure mortgages.

Keywords: business cooperation, economic development prospects, finance, entrepreneurship and investments, corporate strategy, business model innovation

\section{INTRODUCTION}

In a market economy, various ways of attracting resources for investment purposes are used. However, with limited available financial resources, any economic structure always tries to find the best option. In this regard, investments are the most important economic resource that determines the efficiency and competitiveness of economic entities at various levels in the context of modern business cooperation and constant changes. Investment activities contribute to the formation of new jobs; increase the level of income and quality of life of the population. Sustainable economic development in the long term implies an increase in the volume of investments and increase in the effectiveness of investment activities. Investment activities of corporations at the regional level are implemented through the development and implementation of relevant projects [1-3].

Realization of the purpose of research of problems of optimization of investment resources of corporations will allow maximizing efficiency of financial budgets in the 
theoretical consideration and application of the methodology of system design.

Project financing is a mechanism for attracting financial resources to the economy of the regions, if the basis for the return of investment is the profit from a particular project, considered regardless of the results of the financial and economic activities of the initiators of the project [13-16]. Objects of investment are a certain plan embodied by this or other economic structure, but not all economic activity of the borrower. When implementing an investment project, it is necessary to create a special design firm that ensures coordination, legal and economic coherence of decisions and acts as the project operator. This allows improving business processes, investment flows, taxation, and project risk management. In addition, the identification and allocation of the intended risks among the participants, as well as the availability of an appropriate security package and collateral, are considered necessary components of the financial mechanism.

The systematic approach in this case is implemented with the definition, identification of the entry and exit of the economic system, which subsequently cause its structuring. Without the determination of the input and output of the system, the organization is not possible, because development resources or functional affiliation are not identified. This process determines the contour in the environment of existence of the considered system.

The organization of management should be considered as a rational combination of elements of the control system with the object of management for the implementation of a certain goal. The organization of financial work at the enterprise can be represented as the subsystem managing object which provides its functioning (achievement of reference points in spheres of financial activity, performance of functions of financial resources) for achievement of the purpose of ensuring reproduction of financial resources $[17,18]$. When considering approaches to determining the purpose of functioning of an economic entity, the model of market value maximization is relevant. In this case, the value (forming the investment resources of the subject) receives an increment, implementing the mechanism of financial growth of the system.

The polar system States that form the understanding of the characteristics of its main parameters are: 1) chaos (orderly organization structural parts missing) - organization (structure elements are ordered to achieve the goal of the system); 2) lack of concentration value in the system (it is distributed in space, time) - the maximum cost value of education (involving the accumulation value in the system). Chaos implies no concentration of value, and organization implies concentration of value in the system.

The opposite concepts that characterize these processes are: "entropy "(lack of order, disorganization, and chaotic system) and "negentropy" (identified with information and involves the processes of structuring). The derived concepts are: information asymmetry, market formation, cost concentration of segments. From this point of view, the systematic approach of research involves ordering, structuring, 
A comprehensive view of the management problem formalization of information, which contributes to the scientific Outlook.

For an exhaustive understanding of the process of management impact on investment resources, it is necessary, in addition to internal structure-forming factors, to identify factors of external order - they are generating for the system, supporting its development:

1) the right to allocate resources (certain property rights). This factor is surpassed, causing its creation (institution, equity), recharge resources;

2) external sources of financial resources imply the receipt of funds from the outside. It is natural to establish value relations with the financial and credit sphere for the accumulation and receipt of value;

3) the Manager managing the system also acts as surpasses factor. Unlike the owner, he enters the immediate environment of the system. The Manager selects the elements and forms the structure of the system to fully meet the requirements of the external environment. This factor (in terms of creativity) contributes to the negentropy of the system (the flow of ordered information) for its permanent development, the increment of value to the available resources. The third and first factors can be identified to some extent;

4) space and time are the most important coordinates, parameters of the position of the system and its evolution. In space and time it passes stages of development, changing the available characteristics. These characteristics are known in the system approach as the principle of space-time existence of the system. These basic categories reveal the universal forms of existence of the elements and allow us to take into account the historicity, cyclical development of economic systems. The relationship of these basic categories is discussed in the context of the characteristics of "speed", which is the resulting characteristics of the evolution of the object, which determines the parameters of his life, allows adjustments of the life cycle stages, and performance objective (e.g., maximizing business value).

From these positions, investment resources can be considered in terms of past (realized costs), present (available funds), future (future costs). In addition, both the elements and their set as a whole change. "Time" affects both the value of a unit of financial resources, and the entire system, passing such stages of development as the emergence, formation, maturity, destruction, disappearance. The law of synergetic assumes establishment of optimum parameters of functioning of components of system (parameters, interdependence of elements, their correspondence, and change in time) from the point of view of maximization of final result. This situation is typical for such objective characteristics of financial resources as value, which determines the different methods of business valuation.

The system of financial resources is characterized by cyclical development, which is due to the implementation of the principle of historicity of development. By investigating cycles and their causes, it is possible to control the state of the system [19-20]. involves detailing a set of elements of the management system-in addition to financial managers for the implementation of the management process, other components are needed: management bodies, information, organizational and computer technology, management technology, management personnel. Information, organizational and computer technology, management technology are considered as elements of the means of labor, and management personnel - as a labor force, through which the subject of management affects the subject of labor - investment resources. Systematic research, and subsequently the design of relationships are possible only taking into account the coverage of all structural parts and relationships. Synergetic processes in systems of different levels led to the emergence of business intelligence systems, the basis for the formation of which were information, organizational, computational components. The information component of the systems led to the emergence of the information economy (post-industrial stage of development of society).

The functioning of the financial system is a movement, the interaction of all its elements in time and space, causing qualitative changes in the structure and condition of the object of management.

Interaction of elements in this or that formation forms subsystems in which one of elements is considered as the leading, and others - subordinated. For example, the relationship "controls" with other elements forms a subsystem "organizational management structure". As part of the financial system can be identified subsystems: "organizational structure of management", "structure of the information subsystem", "structure of organizational and computer technology", "structure of management technology", "structure of personnel management", "structure of the subsystem of financial resources".

A comprehensive view of the management problem involves detailing a set of elements of the management system-in addition to financial managers for the implementation of the management process, other components are needed: management bodies, information, organizational and computer technology, management technology, management personnel. Information, organizational and computer technology, management technology are considered as elements of the means of labor, and management personnel - as a labor force, through which the subject of management affects the subject of labor - investment resources. Systematic research, and subsequently the design of relationships are possible only taking into account the coverage of all structural parts and relationships. Synergetic processes in systems of different levels led to the emergence of business intelligence systems, the basis for the formation of which were information, organizational, computational components. The information component of the systems led to the emergence of the information economy (post-industrial stage of development of society).

The functioning of the financial system is a movement, the interaction of all its elements in time and space, causing 
qualitative changes in the structure and condition of the object of management.

Interaction of elements in this or that formation forms subsystems in which one of elements is considered as the leading, and others - subordinated. For example, the relationship "controls" with other elements forms a subsystem "organizational management structure". As part of the financial system can be identified subsystems: "organizational structure of management", "structure of the information subsystem", "structure of organizational and computer technology", "structure of management technology", "structure of personnel management", "structure of the subsystem of financial resources". Functioning of these subsystems has the features caused by priorities of the allocated tasks.

For implementation of administrative influence on investment resources it is necessary to know the characteristic of stages of reproduction process, i.e. to have a quantitative idea of cost formation. Such information is the rate of accumulated, expended funds. Knowing the norms, it is possible to quantitatively describe the processes of transferring elements from one stage to another, and therefore plan the investment transformation of the system. In the process of such translation, it becomes necessary to measure the results achieved and to analyze the existing deviations from the indicators of the plan. Based on the results of the analysis, it becomes possible to purposefully and reasonably influence the processes taking place in the system in order to achieve the planned investment indicators.

\section{RESULTS}

The formalized part of the process of management of investment resources is a sequence, in each stage of the reproduction process of elements, procedures: regulation, planning, accounting, analysis, regulation. Their closed, repetitive nature is considered as phases of the management cycle. The method of the economic entity, the relationship of the system components (components of different levels and specificity) is advisable to define as a financial mechanism of the economic entity, ensuring its optimal functioning. Project financing is a system that includes many elements (participants, objects of financing, contracts, risk management, infrastructure), which are closely interrelated and ensure the efficiency of the movement of financial flows. It is necessary to study the characteristics of the current stage of development of project financing, focused on sustainable economic growth, innovative development and the global economy. Implementation of investment financing projects with the participation of the state and private investors at the regional level is a promising mechanism in conditions of insufficient infrastructure development and limited budgetary sources of financing. It is advisable to make greater use of the opportunities of public-private partnership. Among the promising mechanisms for financing investment projects with the participation of the state are: the mechanism of deferred tax payments; the life cycle contract; the mechanism of infrastructure mortgages.
The studied features of the prospects of functioning of the system of investment activity of industrial corporations in the conditions of modern economic development and cooperation reveal the complexity of this problem. Note that the understanding of the nature and design of the financial mechanism of Corporation is accomplished with all the selected configurations, which combined, can achieve full disclosure of the functioning of the investment model. Each of the selected configurations shows a promising direction of further scientific constructions, which in the future can lay the basis for the relevant theory of research-this is the novelty and the author's contribution to the study. This fact should be taken into account when designing investment, structuring the activities of economic entities at any level of the economy.

\section{REFERENCES}

[1] K. Alam, M. Shahiduzzaman, "Shaping our economic future", An eimpact study of small and medium enterprises in the Western Downs Region, Queensland, University of Southern Queensland, Toowoomba, 2014.

[2] "Strategy+Business", 12 September 2016 [Electronic resource]. Available at: http://www.strategybusiness.com/article/Siemens-CEOJoe-Kaeser-on-the-Next-Industrial-Revolution?gko=efd41.

[3] C. Velu, "A systems perspective on business model evolution: the case of an agricultural information service provider in India", Long Range Plan, 50 (5), 2017, pp. 603-620.

[4] E. Cameron and M. Green, "Making sense of change management: a complete guide to the models, tools and techniques of organizational change", Kogan Page Publishers, 2015.

[5] H. Volberda, F. Van den Bosch, K. Heij, "Reinventing Business Models: How Firms Cope with Disruption", Oxford: Oxford University Press, 2018.

[6] P. A. Levchaev, "Finance companies: textbook", M.: INFRA-M, 2017, $386 \mathrm{p}$.

[7] P. A. Levchaev, "Corporate Finance and business valuation", Riga, Latvia, European Union: LAP LAMBERT Academic Publishing, 2019, 192 p.

[8] P. A. Levchaev, "The value of Your business", Symbolic interpretation of the financial resources for the evaluation of the business, Germany: Scholar`s Press, 2016, 45 p.

[9] N. Gorenflo, "How Platform Coops Can Beat Death Stars Like Uber to Create a Real Sharing Economy", 2015 [Electronic resource]. Available at: http://www.shareable.net/blog/how-platform-coops-can-beat-deathstars-like-uber-tocreate-a-realsharing-economy.

[10] G. Grigore, M. Molesworth, and R. Watkins, "New Corporate Responsibilities in the Digital Economy", In Corporate Social Responsibility in the Post-Financial Crisis Era, Switzerland: Springer International Publishing, 2017, pp. 41-62.

[11] P. Aghion, J. Cai, M. Dewatripont, L. Du, A. Harrison, and P. Legros, "Industrial policy and competition. Am Econ J Macroecon", American Economic Association, 2015, 7 (4), pp.1-32.

[12] D. Korschun and S. Du, "How Virtual Corporate Social Responsibility Dialogs Generate Value", A Framework and Propositions, Journal of $\begin{array}{llll}\text { Business } & \text { Research, } & \text { 2013, }\end{array}$ pp. 1494-1504.

[13] R. Baldwin and S. Evenett, "Value creation and trade in 21st century manufacturing: what policies for UK manufacturing? In Greenaway D (ed) The UK in a global world", CEPR, London, 2012, pp. 71-128.

[14] J. B. DeLong and L.H. Summers, "How important will the information economy be? Some simple analytics", 2001 [Electronic resource]. Available at: http://www.j-bradforddelong.net/econ_articles/summers_jh_2001/ jh_analytics.pdf (accessed 27 June 2016). 
[18] D. J. Teece and S. Leih, "Uncertainty, innovation, and dynamic capabilities: an introduction", Calif. Manag. Rev, 2016, 58 (4), pp. 5-12.

[19] D. J. Teece, "Business models and dynamic capabilities", Long. Range Plan, 2018, 51 (1), pp. 40-49.

[20] D. J. Teece and G. Linden, "Business models, value capture, and the digital enterprise", J. Org. Des, 2017, 6 (1), pp. 1-14.

[17] G. Westerman and D. Bonnet, "Revamping your business through digital transformation", MIT Sloan Manag. Rev, 2015, 56 (3), 10 p. 